\title{
Correction to: A basic hypoplastic constitutive model for sand
}

\author{
Wei $\mathrm{Wu}^{1,2}$ (1) $\cdot$ Jia Lin $^{1,2} \cdot$ Xuetao Wang ${ }^{1,2}$
}

Published online: 30 October 2017

(C) The Author(s) 2017. This article is an open access publication

\section{Correction to: Acta Geotechnica \\ DOI 10.1007/s11440-017-0550-4}

In the original publication of the article, the placement of the symbol sigma in the last term of Eq. (6) is incorrect. The correct equation should read as given below:

$\stackrel{\circ}{\boldsymbol{\sigma}}=c_{1}(\operatorname{tr} \boldsymbol{\sigma}) \dot{\boldsymbol{\epsilon}}+c_{2} \frac{\operatorname{tr}(\boldsymbol{\sigma} \dot{\boldsymbol{\epsilon}})}{\operatorname{tr} \boldsymbol{\sigma}} \boldsymbol{\sigma}+c_{3} \frac{\boldsymbol{\sigma}^{2}}{\operatorname{tr} \boldsymbol{\sigma}}\|\dot{\boldsymbol{\epsilon}}\|+c_{4} \frac{\boldsymbol{\sigma}^{* 2}}{\operatorname{tr} \boldsymbol{\sigma}}\|\dot{\boldsymbol{\epsilon}}\|$

Open Access This article is distributed under the terms of the Creative Commons Attribution 4.0 International License (http:// creativecommons.org/licenses/by/4.0/), which permits unrestricted use, distribution, and reproduction in any medium, provided you give appropriate credit to the original author(s) and the source, provide a link to the Creative Commons license, and indicate if changes were made.

The online version of the original article can be found under doi:10.1007/s11440-017-0550-4.

\section{Wei $\mathrm{Wu}$}

wei.wu@boku.ac.at

1 Institution of Geotechnical Engineering, University of Natural Resources and Life Sciences, Vienna, Austria

2 Tunneling Engineering, Technical Center, Ed Züblin AG, Stuttgart, Germany 